\title{
Trespassing on Finnish railways: identification of problem sites and characteristics of trespassing behaviour
}

\author{
Anne Silla • Juha Luoma
}

Received: 11 September 2008 / Accepted: 27 November 2008 / Published online: 10 December 2008

(C) European Conference of Transport Research Institutes (ECTRI) 2008

\begin{abstract}
Introduction This study identified the sites of frequent trespassing on Finnish railways, investigated trespassing behaviour at selected sites, and explored opinions about preventive measures.

Materials and methods The study consisted of qualitative and quantitative part. The qualitative part included a survey directed at engine drivers and trespassers interviews whereas the quantitative part was constituted by a more detailed analysis on trespasser behaviour and characteristics of trespassers of selected sites. First, sites with frequent trespassing were explored by a survey directed at engine drivers. In addition, the drivers were also asked for suggestions of potential preventive measures. Second, three locations were chosen for a more detailed investigation which included the counting of trespassers. Third, trespassers at these locations were interviewed.

Results The results of the survey directed at engine drivers revealed approximately 100 problematic sites. On average about 40 daily trespassers could be observed at selected research sites. The trespassers were typically adults and males. The answers from trespasser interviews showed that the main reason for trespassing is taking a short cut. Half of the respondents assessed that the trespassing is safe and $15 \%$ assumed that trespassing is legal. Furthermore, they indicated that the most effective measures to prevent trespassing is fencing the tracks or building an underpass. In fact, the engine drivers usually indicated the same measures.
\end{abstract}

A. Silla $(\bowtie) \cdot$ J. Luoma

VTT Technical Research Centre of Finland,

P.O. Box 1000, 02044 VTT Espoo, Finland

e-mail: silla@iww.uni-karlsruhe.de

e-mail: anne.silla@vtt.fi

J. Luoma

e-mail: juha.luoma@vtt.fi
Discussion In conclusion, various physical measures should be considered as effective and acceptable preventive measures. However, since many trespassers considered trespassing to be safe and assumed that trespassing is legal, it is worth considering information campaigns as an additional preventive measure.

Keywords Railway · Safety · Trespassing · Survey · Observation $\cdot$ Interview

\section{Introduction}

Collision between trains and pedestrians is a leading fatal train-related accident type worldwide and therefore many studies have argued that trespassing is one of the most important railway safety issues (see e.g. [6, 7, 12]). Trespassers endanger their own health and cause disturbance to the railway traffic. Based on the Finnish statistics [1], a total number of 68 fatalities caused by railway accidents could be identified for the considered years of 2004-2006. If the road users, the railway passengers and the personnel involved in railway accidents are excluded, 46 fatalities (i.e. $68 \%$ of all fatalities) can, most probably, be assigned to trespassers. Finland is not the only country where such a high proportion of people killed in railway accidents are trespassers. In the European Union more than half of all fatal injuries were sustained by trespassers in 2006 [9]. Possible suicide cases have also been assessed but they have been excluded from the above fatalities. The suicides differ from the trespasser fatalities, since instead of accidents they consist of persons intentionally putting themselves in a situation where they would be struck by a train. However, the determination of whether or not deaths in railway systems are accidents or suicides is not always easy since 
in many cases information necessary to make a definitive classification is not sufficient. [10].

According to Finnish law crossing the railway line is only permitted at sites especially marked for that purpose. The penalty for breaking the law is a fine [2]. However, the law does not indicate any specific amount of the fine. Another form of trespassing is illegal walking or loitering in the railway area. But although trespassing is illegal, clear and regularly used footpaths over the railway line can be found at many places. Consequently, it is reasonable to assume that trespassing is frequent.

Not too much relevant research has been conducted in this area. In Canada there is A Community Problem-solving Guide, which was developed during the community trespass prevention programme [5]. The programme aims at reducing railway trespassing and crossing incidents and related injuries and deaths. Local problem-solving committees have been formed to gather information about trespassing to investigate the contributing factors of trespassing at a specific location. According to the community problemsolving guide, these contributing factors vary in each community. The guide also highlights that the effective long-term solutions to trespassing problems can be realized by identifying the underlying factors of trespassing at a specific location. The responses should also be tailor-made to each location in order to make the implemented measures effective. As part of the programme C.A.R.E. (Community, Analysis, Response and Evaluation) problem solving model was developed to help communities in identifying and addressing the underlying cause(s) of trespassing. The model included a template for Trespasser Interviews to collect more detailed information about the problem. This template was used as an example when developing the questionnaire for the trespasser interviews in the present study.

A British study investigated through data analyses and field research factors driving trespass via platform ends and solutions to reduce the risk of this occurring [13]. The results of the study showed a number of factors that were likely to increase the risk of trespass at a location. In this context particularly the use of alcohol, avoidance of fairs barriers and station design and layout can be mentioned.

The awareness of the illegality of walking across the tracks as well as the perception of risk and the trespassers' attitudes have been studied using observations and anonymous surveys in New Zealand. Lobb et al. [8] evaluated a programme of educational and environmental interventions designed to reduce the incidence of illegal and unsafe crossing of the rail corridor at a suburban station in Auckland. Another study by Lobb et al. [7] scrutinised a programme of intervention designed to reduce the incidence of illegal and unsafe crossing of a rail corridor at a city station by boys on their way to and from the adjacent high school.
It is clear that there is a need for collecting information on railway trespassers as a basis for accident prevention. Characterising the trespassers has previously focused on profiling the trespassers based on reported incidents and fatalities (see e.g. $[3,12,13]$ ). However, it is important to make the distinction between the characteristics of trespassers in general and the characteristics of the subset of trespassers who sustain fatal and non-fatal injuries. Evidently the total number of trespassers is much larger than the number of casualties [14].

In order to tackle the problem to reduce the number of trespasser fatalities it is important to broaden the knowledge related to trespassing. Therefore, the aim of this study was to identify the sites of frequent trespassing on Finnish railways, to investigate trespassing behaviour and characteristics at selected sites, and to explore opinions about possible countermeasures to prevent trespassing.

\section{Method}

The study consisted of qualitative and quantitative part. The qualitative part included a survey directed at engine drivers and trespassers interviews whereas the quantitative part was constituted by a more detailed analysis on trespasser behaviour and characteristics of trespassers of selected sites.

First, the survey was conducted to explore the sites were trespassing occur. In the survey form, drivers were asked about locations where they have frequently observed trespassers and for their suggestions of potential preventive measures. The survey forms were delivered to all workplaces across the whole railway network in Finland. Thus, the engine drivers could focus on problematic sites in the area where they usually drive trains. The survey form included a map of the area close to the workplace and a table where problematic sites were to be listed. In addition, drivers could refer to problematic sites elsewhere in Finland. Finally, the engine drivers could propose preventive measures. The survey forms were delivered to the engine drivers' mailboxes in their workplaces, making them available to all engine drivers.

In addition to collecting engine drivers' opinions about potential safety measures, the survey results were used to choose candidate locations for the next phase of the study. The most suitable locations for further investigation were identified by preliminary site observations. A total of more than 10 locations from the capital area and the Lappeenranta area were selected. The final selection criteria included the following: (a) it is possible to execute measurements with the help of cameras with motion detectors, (b) the amount of trespassers is relatively high and (c) the legal rail crossing site is located less than $500 \mathrm{~m}$ from the trespassing location. 
The most suitable sites for further investigation were all found in the city of Lappeenranta. The Lappeenranta area is challenging, because the tracks divide the city into two parts. Based on preliminary site observations in Lappeenranta over a $4 \mathrm{~km}$ stretch of track, a total of 12 trespassing locations were found of which three were selected. At each location the official route is no more than $300 \mathrm{~m}$ away. The research location 1 is situated near ice hall and outdoor routes, location 2 is situated near school and location 3 is situated closest to the main city centre. During the working days more than 50 trains are passing this railway section, out of which 14 are passenger trains. The speed for passenger trains in the railway section varies between 80 and $140 \mathrm{~km} / \mathrm{h}$.

The quantitative part was constituted by analyses of three selected sites. Trespassers at these sites were counted with cameras equipped with motion detectors. The motion detectors covered the path used by trespassers, and whenever movement was detected the camera took 15 digital pictures at intervals of $1 \mathrm{~s}$. The camera functioned independently and only required the batteries to be changed once a week. The measurements were taken in May, allowing data to be collected almost around the clock due to the ambient lightness in Finland at that time of year. Only a couple of hours at night were missed because of darkness. In addition to counting trespassers, the characteristics of trespassers such as gender, age, the number of people who were trespassing together and whether they carried something were classified and documented.

In the third part, approximately 4 months later, some trespassers at the same research locations were interviewed. The questions were based on the forms used in the
Canadian study shortly introduced above [5]. The interview specifically focused on trespassers' movements in the railway area, their possibilities and willingness to change their routes, how dangerous they think trespassing is, and their awareness of regulations regarding walking in the railway area. In addition, they were asked what would stop them from trespassing.

The interviews, which were conducted over 2 days at each of three locations, took place between 7:30 A.M. and 17:00 P.M. In total, 46 out of 108 trespassers were interviewed. Some trespassers were not interviewed for of the following reasons: they were identified more than once, some of them were speaking on their mobile phone, interviewers were too occupied, or trespassers were too busy.

Figure 1 illustrates the general methodological approach:

\section{Results}

\subsection{Survey of engine drivers}

In total, 1,500 survey forms were distributed to engine drivers. Ninety-six forms were returned that included 404 problem sites (Table 1 ). The response rate was only $6 \%$ and hence the results were considered as qualitative results. However, the low response rate was not considered a major problem regarding the representativeness of the results, because at least one survey form was returned from each workplace. Therefore it was presumed that at least the worst problem sites on the railway network were identified.

Because of a substantial overlap among identified sites, approximately 100 unique locations could be identified.
Fig. 1 Methodological approach

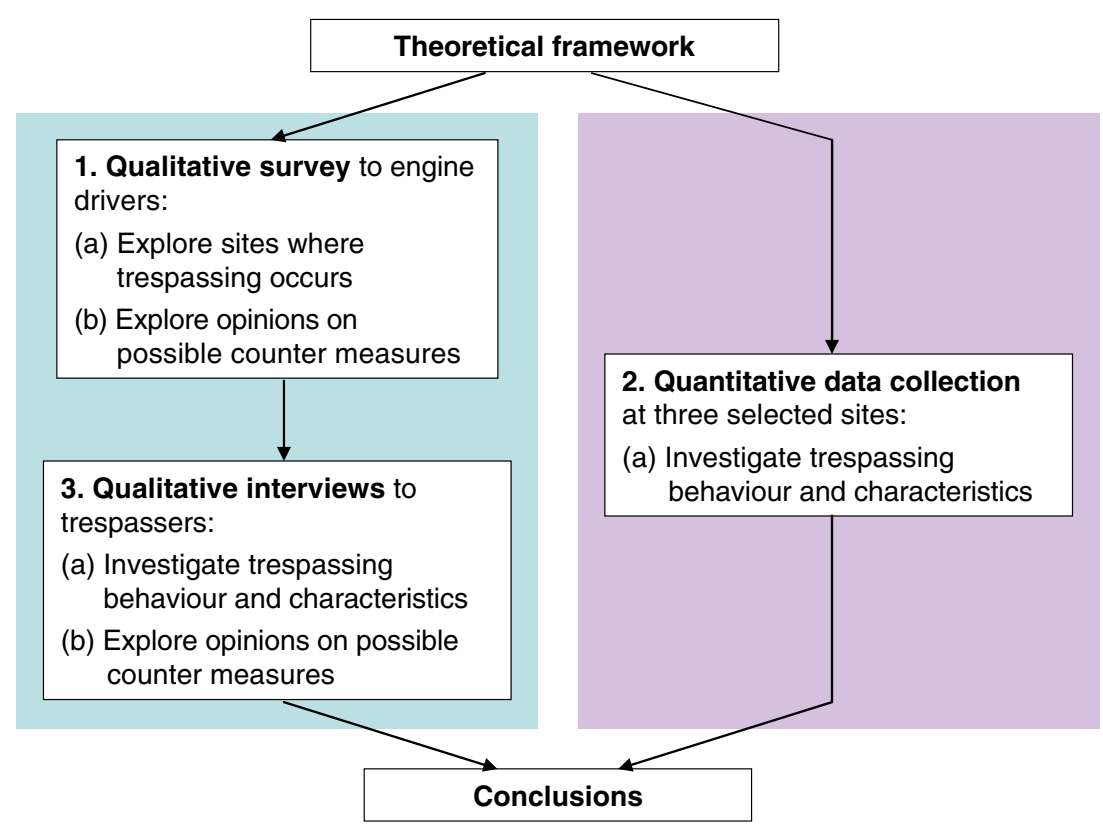


Table 1 Number of workplaces of engine drivers, number of returned survey forms and number of reported problem sites by area

\begin{tabular}{lccc}
\hline $\begin{array}{l}\text { Area of } \\
\text { country }\end{array}$ & $\begin{array}{l}\text { Number of } \\
\text { workplaces of } \\
\text { engine drivers }\end{array}$ & $\begin{array}{l}\text { Number of } \\
\text { returned survey } \\
\text { forms }\end{array}$ & $\begin{array}{l}\text { Number of } \\
\text { reported } \\
\text { problem sites }\end{array}$ \\
\hline Southern & 4 & 25 & 123 \\
Western & 5 & 21 & 127 \\
Central & 3 & 10 & 26 \\
Eastern & 4 & 30 & 76 \\
Northern & 5 & 10 & 52 \\
Total & 21 & 96 & 404 \\
\hline
\end{tabular}

Trespassing seems to concentrate near big cities where the population density is high and rail traffic is dense. In addition, trespassing was seen as a communal problem. Based on the returned survey forms it was possible to identify some locations where people from all the age groups were frequently trespassing. At these locations people do not necessarily consider trespassing as wrong and they may not understand the risk incurred by it.

As the most effective preventive measures engine drivers considered fencing, followed by information campaigns, prohibitive signs, imposition of a fine and building an underpass or overpass. Information about the danger of trespassing should be delivered to children in nearby schools and to people living close to railway tracks. The engine drivers also proposed information campaigns in the local papers and on radio and television, and placing fact sheets about the danger of trespassing close to railway tracks. Furthermore, the police should also make occasional enforcement campaigns at sites where trespassing occurs frequently. During those campaigns they should impose fines that are big enough to act as effective deterrents. Finally, camera surveillance and increasing the number of guards were also suggested as complementary forms of preventing trespass.

The results suggest that engine drivers strongly supported fencing. However, fencing alone may not be adequate for all sites. The fences are considered to be effective if they are high and strong enough. In addition, they should be extended over such a long area that they are not easy to go around. Ideally, fences should be built in a way that they redirect potential trespassers to the legal pedestrian crossing. The effect of fences could be increased by other measures (e.g. deep trenches on both sides of the fence).

The engine drivers also indicated that old, disused level crossings are problematic. Specifically, they reported that people are still using these sites despite their use no longer being legal. This suggests that old roads leading there should be removed. The engine drivers also suggested that some of the sites, where trespassing occurs a lot, should be made legal pedestrian crossings by improving the visibility of the sites and installing alarm equipment.

\subsection{Trespasser interviews}

Trespassers at the three selected locations were interviewed. The interviewed trespassers consisted of adults (48\%), youngsters $(37 \%)$ and elderly people (15\%). In addition, the interviewers observed some children trespassing, but in all cases they were with adults or elderly people, who were chosen for the interview. The reasons for trespassing were asked with an open question rather than alternatives, and the interviewees were able to indicate as many reasons as they wanted. Although the official routes were not more than $300 \mathrm{~m}$ away at each location, $80 \%$ of interviewees indicated that the most common reason for trespassing was that the route was the shortest and fastest alternative. Other specific answers included that it was easy to use the route because there was already an existing path $(9 \%)$, and that it had become a habit (11\%) to use a specific route. Some of the trespassers also indicated that they had been using the route for many decades.

Most people were trespassing while going shopping, jogging, or on their way to school or work. The answers differed somewhat between locations.

The trespassers were also asked about the frequency of their trespassing (Table 2). Thirty-five percent of all respondents trespassed daily or almost daily. It is significant that $67 \%$ of all respondents answered that they trespassed at least once a week. This finding suggests that in these selected locations the majority of trespassers are those for whom trespassing is a habit and the paths across the railway lines are part of their normal routes, although they were aware of the closest official routes across the railway line. Furthermore, based on the answers people are aware that trespassing occurs a lot in the Lappeenranta area.

The trespassers were also asked what they thought were the best preventive measures and what would stop them from trespassing. The respondents were allowed to indicate as many countermeasures as they wanted. First, they could spontaneously suggest different measures, after which the interviewer provided options (listed in Table 3) and the possibility to complement their answers. Both the sponta-

Table 2 Frequency of trespassing based on interviews

\begin{tabular}{lc}
\hline Frequency of trespassing & Number of respondents \\
\hline Daily/almost daily & 16 \\
2-4 times a week & 9 \\
Once a week/weekly & 6 \\
A couple of times a month & 1 \\
Once a month & 3 \\
A couple of times every 6 months & 2 \\
Once a year & 2 \\
Other & 7 \\
Total & 46 \\
\hline
\end{tabular}


Table 3 Number of indicated countermeasures

\begin{tabular}{llllr}
\hline \multirow{2}{*}{ Measure } & \multicolumn{2}{l}{ Number of answers by location } & \multirow{2}{*}{ Total } \\
\cline { 2 - 4 } & 1 & 2 & 3 \\
\hline Fencing & 3 & 3 & 17 & 23 \\
Underpass/overpass & 4 & 5 & 2 & 11 \\
Imposition of a fine/enforcement & 0 & 2 & 2 & 4 \\
Prohibitive sign & 1 & 0 & 2 & 3 \\
Information given through education & 0 & 0 & 2 & 2 \\
Home delivered information & 0 & 0 & 2 & 2 \\
Media & 0 & 0 & 2 & 2 \\
Landscaping & 0 & 0 & 0 & 12 \\
Not able to define/nothing & 4 & 6 & 4 & 61 \\
Total number of suggested countermeasures & 12 & 16 & 33 & 46 \\
Total number or interviewed trespassers & 10 & 14 & 22 & \\
\hline
\end{tabular}

neously given suggestions and those based on the interviewer's list were combined (Table 3 ).

The most frequently suggested measures included building a fence or an underpass/overpass. Fencing was relatively more frequently indicated at location 3 than at locations 1 and 2. The opposite applies to the building of an overpass or underpass. This difference most likely resulted from the distance to the closest official crossing site being shorter at location $3(150 \mathrm{~m})$ than at locations 1 and $2(200-$ $300 \mathrm{~m})$. Specifically, the results suggest that people were more willing to accept fencing if the distance to the closest official crossing site was relatively short, but in the case of a relatively long distance they rather preferred an overpass or underpass. In addition to the above measures, enforcement or imposition of a fine, installation of a prohibitive sign and information provided by various means were supported.

Half of the respondents assessed that the trespassing is either completely or fairly safe (Fig. 2). Many of the interviewees considered trespassing safe when they are careful. Furthermore, many of them responded that they are able to cross the tracks safely and were more worried about children, elderly people, drunken people and those whose attention is somehow distracted. In contrast, about $17 \%$ of the interviewees consider trespassing very dangerous.

Overall, 59\% of the respondents considered trespassing illegal, $15 \%$ considered it legal and $26 \%$ did not know. A few
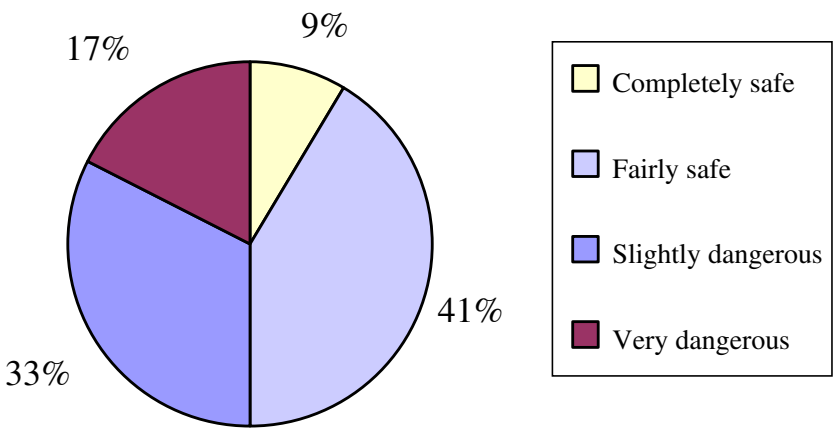

Fig. 2 Understanding of the danger of trespassing respondents indicated that they had never even thought about the legality of their act. Some of the respondents also said that it must be legal, as there is no sign to indicate otherwise.

In addition, at the end of the interview trespassers were able to share their views about trespassing. One of the things that emerged is that people are aware that trespassing occurs a lot in the Lappeenranta area.

\subsection{Trespasser counts}

Trespassers at the three selected sites were counted with cameras equipped with motion detectors. Table 4 shows the number of trespassers by location and date.

Table 4 Number of trespasses by location and date (zero indicates the inoperability of the camera)

\begin{tabular}{lllll}
\hline Date & Location & & Total \\
\cline { 2 - 4 } & 1 & 2 & 3 & \\
\hline 15.05 .2006 & 12 & 20 & 34 & 66 \\
16.05 .2006 & 22 & 50 & 93 & 165 \\
17.05 .2006 & 0 & 38 & 83 & 121 \\
18.05 .2006 & 0 & 46 & 60 & 106 \\
19.05 .2006 & 0 & 43 & 79 & 122 \\
20.05 .2006 & 0 & 19 & 53 & 72 \\
21.05 .2006 & 0 & 40 & 72 & 112 \\
22.05 .2006 & 28 & 40 & 63 & 131 \\
23.05 .2006 & 19 & 22 & 51 & 92 \\
24.05 .2006 & 12 & 29 & 76 & 117 \\
25.05 .2006 & 12 & 29 & 73 & 114 \\
26.05 .2006 & 15 & 14 & 91 & 120 \\
27.05 .2006 & 11 & 0 & 71 & 82 \\
28.05 .2006 & 12 & 0 & 55 & 67 \\
29.05 .2006 & 20 & 30 & 68 & 118 \\
30.05 .2006 & 33 & 25 & 54 & 112 \\
31.05 .2006 & 0 & 30 & 88 & 119 \\
01.06 .2006 & 0 & 29 & 54 & 83 \\
02.06 .2006 & 0 & 15 & 20 & 35 \\
Total & 197 & 519 & 1,238 & 1,954 \\
Percentage & $10 \%$ & $27 \%$ & $63 \%$ & $100 \%$ \\
\hline
\end{tabular}


During 19 days of measurement a total of 1,954 trespasses were detected. More than half of them occurred at location 3. During days when the camera was working all the time, some 70 trespasses occurred at location 3 . The corresponding numbers at location 1 and 2 were 18 and 34, respectively. This amounts to roughly 40 daily trespasses by location on average.

Trespassing was most common between 11 A.M. and 7 P.M. The quietest phase was between 11 P.M. and 6 A.M., when only $2.3 \%$ of trespasses occurred.

Sixty-three percent of trespassers were males. Furthermore, the results showed that approximately $10.1 \%$ of trespassers were children (12 years or younger), $35.6 \%$ were youngsters (12 to 20 years) and $54.3 \%$ were adults or elderly people (Fig. 3). The majority of trespassers at all locations were adults.

Overall, $69.9 \%$ of the trespassers were alone and $23.2 \%$ of them were in groups of two. Larger groups were very rare. Most trespassers $(55.3 \%)$ were trespassing without carrying or having anything with them, 31.7\% were carrying their bicycle, $11.3 \%$ were with their $\operatorname{dog}(\mathrm{s}), 1.6 \%$ were equipped with poles (i.e. Nordic walking) and a few trespassers were trespassing with something else, like a pram or scooter.

There were some differences between the three locations concerning, what trespassers were carrying. For example, most trespassers equipped with poles were found at location 1 where there is a nearby outdoor route. However, these differences did not lead to any obvious conclusions, although they showed in general that local aspects may affect the characteristics of trespassing.

\section{Discussion}

The survey directed at engine drivers was used to identify the most problematic sites for preliminary site observations to choose the research locations for this study. In addition, the engine drivers were asked the potential preventive measures to prevent trespassing. The main results of the engine driver interviews showed that in most cases the most powerful

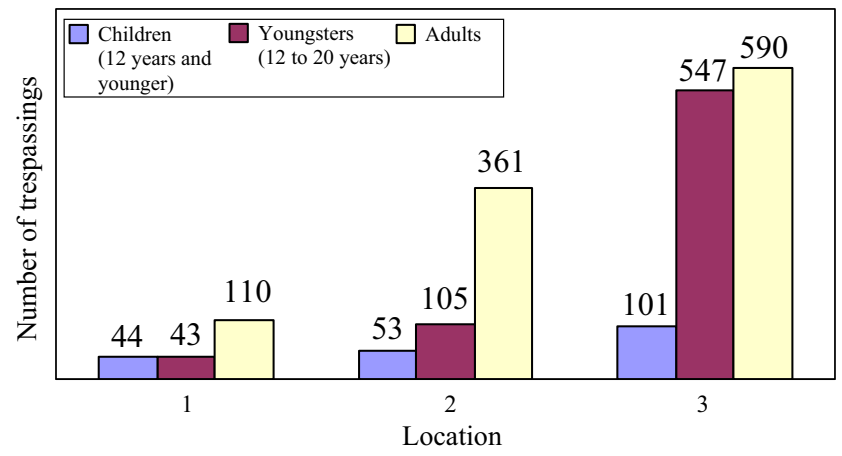

Fig. 3 Number of trespasses by age group and location preventive measures would be fencing (high, strong and long fences possibly combined with other measures), information campaigns, prohibitive signs, imposition of a fine and building an underpass or overpass. Furthermore, camera surveillance and increasing the number of guards can be established as a complementary form of preventing trespassing.

Based on the interviewed trespassers the most effective measures to prevent trespassing would be fencing the tracks or building an underpass. However, building an underpass did not belong to the most frequently suggested countermeasures among engine drivers. This finding suggests that engine drivers were more realistic while including the cost of countermeasures in their assessment. Specifically, it is reasonable to assume that engine drivers know that the resources available for countermeasures are limited and building an underpass is one of the most expensive ones. (The Finnish Rail Administration is responsible for building and maintenance of railway infrastructure in Finland.) The trespassers primarily suggested countermeasures that were the most convenient for them.

The suggestions for preventive measures indicated by the trespassers were somewhat related to the locations. The measures thought to be effective at one location were not considered so effective at another. This result is supported by earlier studies that also showed that there is no single generic solution for preventing a trespass; on the contrary, a trespass tends to be specific to a location, and solutions should be tailored to specific locations and factors in order to make the implemented measures effective (see e.g. [5, $13,14])$. According to the answers in this study, the main factor that determined the suggested countermeasures in current research locations was distance to the closest official crossing site.

The trespasser interviews also showed that the main reason for trespassing is taking a shortcut, which confirms the results of earlier studies (see e.g. [8, 13]). Specifically, the interviewees indicated that the route across the railway tracks is the shortest and the fastest alternative. Many of them have used the route for years, and according to them it is easy to use because there are already clear paths across the railway tracks.

More than $17 \%$ of the trespassers considered that trespassing is very dangerous. Nevertheless they were trespassing even though the official crossing was fairly close (less than $300 \mathrm{~m}$ away). This result suggests that trespassers are aware of the accident risk, but are not willing to use the longer route. However, it is possible that the difference between actual behaviour and opinions was because of the interview. Presumably at least some of the interviewees wanted to appear more responsible than they actually are.

However, on the other hand, half of the trespassers assessed that trespassing is either fairly or completely safe. Many of the trespassers considered that trespassing is safe 
when they are careful. They indicated that they are able to cross the tracks safely but other trespassers' behaviour may be risky. Indeed, previous research has shown that the common belief is that we are less likely to suffer negative events than our peers. This effect is called illusory invulnerability and it allows us to take risks, because the paradoxical belief is that "It will not happen to me." [4].

The results of trespasser counts showed approximately 40 daily trespasses at the selected locations, on average. The trespassers were typically adults and males. The finding that males are trespassing more frequently than females is in line with previously obtained results (see e.g. $[8,13])$. Trespassers are frequently alone and not carrying anything with them. These findings are useful for the design of preventive measures. Specifically, it is possible to assume that the trespassers who trespass with their $\operatorname{dog}(\mathrm{s})$, for example, are on a leisure trip and might be more willing to change their route, as they are not necessarily under as much time pressure to use the shortest alternative. It could also be assumed that people who are carrying their bicycle while trespassing could be more willing to change their route if a physical countermeasure (e.g. fence or landscaping) is built.

In conclusion, given that a substantial number of interviewed trespassers considered trespassing to be safe and so many trespassers assumed that trespassing is legal, it is worth considering information campaigns to raise awareness of the illegality of trespassing and the dangers related to it as one form of preventing trespassing. Finnish Rail Agency is participating in the Operation Lifesaver, which is a non-profit, international, public education programme (originally from the United States) to prevent collisions, deaths and injuries at highway-rail grade crossings and on railroad rights-of-way [11]. Therefore, the support of Operation Lifesaver should be considered when campaigning to prevent trespassing.

In addition to information campaigns, various physical measures (e.g. overpasses and underpasses, fencing, prohibitive signs) should be considered as effective and acceptable preventive measures although engine drivers somewhat hesitated to recommend underpasses. It is also possible to reinforce information campaigns by combining them with physical measures to have a greater influence on trespassers' behaviour.

Furthermore, the cameras with motion detectors introduced in this study appeared to be an efficient method to collect information concerning trespassing. Based on the collected data it was possible to quantify the trespass and collect information concerning the characteristics and behaviour of trespassers in the selected research locations. Furthermore, the conducted survey and interviews enabled to see the problem from the point of view of engine drivers and trespassers. The knowledge received during this study helps practitioners and researchers to better understand the problem when developing effective countermeasures.
It must also be noted that the results from trespasser counts, concerning e.g. the age and hour distribution, might be biased from the site selection criteria. Therefore, it is important to be careful when generalizing the results outside the research sites.

Given that above conclusions are based on the opinions of a limited sample of engine drivers and trespassers, it is worth noting that there might be additional preventive measures that were unknown to or unstated by the interviewees. Further research is needed to address this aspect in future.

Acknowledgements Appreciation is extended to the Finnish Rail Administration for its support of the research this paper is based on. The paper was finalised while Ms. Silla was working as a visiting research scientist in Transportnet project funded by the European Union. The authors wish to thank Jouni Hytönen, Mikko Kallio and Mikko Poutanen for helping with the data collection, and Veli-Pekka Kallberg and Axel Schaffer for their helpful suggestions on earlier drafts of this paper.

\section{References}

1. Eurostat. Transport. European Commission. http://ec.europa.eu/ eurostat/. Accessed 6 Jun 2007

2. Finlex. Railway Act 555/2006. http://www.finlex.fi/en/. Accessed 6 Jun 2007

3. George FB (2007) Rail-trespasser fatalities, developing demographic profiles. Cadle Creek Consulting. Contracted by Federal Railroad Administration. November 2007

4. Hatfield $\mathrm{J}$ et al (2006) The development of messages and experiences to reduce road-related illusory vulnerability and risky driving for young drivers. Final report for the Motor Accidents Authority of NSW. http://www.irmrc.unsw.edu.au/. Accessed 12 Jun 2007

5. Law W (2004) Trespassing on railway lines - a community problem-solving guide. CD-ROM. In 8th International LevelCrossing Symposium \& Managing Trespass Seminar. Rail Safety and Standards Board, Sheffield, 2004

6. Lobb B (2006) Trespassing on the tracks: a review of railway pedestrian safety research. J Saf Res 37:359-365

7. Lobb B et al (2003) An evaluation of four types of railway pedestrian crossing safety intervention. Accident Anal Prev 35:487-494

8. Lobb B et al (2001) An evaluation of a suburban railway pedestrian crossing safety programme. Accident Anal Prev 33:157-165

9. Lundström A (2008) Accidents to unauthorised persons and suicides. ERA seminar on trespassers on railway lines and suicides 3.4.2008

10. Mishara BL (2007) Railway and metro suicides - undestanding the problem and prevention potential. Crisis $28: 36-43$

11. Operation Lifesaver (2008) Rail safety education. http://www.oli. org/index.php. Accessed 28 Apr 2008

12. Pelletier A (1997) Deaths among railroad trespassers. The role of alcohol in fatal injuries. JAMA 277:1064-1666

13. Rail Safety and Standards Board (2007) Trespass and access via the platform end. Final Report. Halcrow Group Limited in partnership with Human Engineering. http://www.rssb.co.uk/. Accessed 12 Jun 2007

14. Savage I (2007) Trespassing on the railroad. Prepared for research in transport economics: railroad economics. Elsevier, Amsterdam 